\title{
Serum magnesium and calcium levels in relation to ischemic stroke
}

\section{Mendelian randomization study}

Susanna C. Larsson, PhD, Matthew Traylor, PhD, Stephen Burgess, PhD, Giorgio B. Boncoraglio, MD, Christina Jern, MD, PhD, Karl Michaëlsson, MD, PhD, and Hugh S. Markus, DM, FMedSci, for the MEGASTROKE project of the International Stroke Genetics Consortium

Neurology ${ }^{\circledR}$ 2019;92:e944-e950. doi:10.1212/WNL.0000000000007001

\section{Abstract}

\section{Objective}

To determine whether serum magnesium and calcium concentrations are causally associated with ischemic stroke or any of its subtypes using the mendelian randomization approach.

\section{Methods}

Analyses were conducted using summary statistics data for 13 single-nucleotide polymorphisms robustly associated with serum magnesium $(n=6)$ or serum calcium $(n=7)$ concentrations. The corresponding data for ischemic stroke were obtained from the MEGASTROKE consortium $(34,217$ cases and 404,630 noncases).

\section{Results}

In standard mendelian randomization analysis, the odds ratios for each $0.1 \mathrm{mmol} / \mathrm{L}$ (about 1 $\mathrm{SD}$ ) increase in genetically predicted serum magnesium concentrations were 0.78 (95\% confidence interval [CI] 0.69-0.89; $p=1.3 \times 10^{-4}$ ) for all ischemic stroke, 0.63 (95\% CI 0.50-0.80; $\left.p=1.6 \times 10^{-4}\right)$ for cardioembolic stroke, and 0.60 (95\% CI 0.44-0.82; $\left.p=0.001\right)$ for large artery stroke; there was no association with small vessel stroke (odds ratio $0.90,95 \% \mathrm{CI}$ $0.67-1.20 ; p=0.46$ ). Only the association with cardioembolic stroke was robust in sensitivity analyses. There was no association of genetically predicted serum calcium concentrations with all ischemic stroke (per $0.5 \mathrm{mg} / \mathrm{dL}$ [about $1 \mathrm{SD}$ ] increase in serum calcium: odds ratio 1.03, 95\% CI $0.88-1.21$ ) or with any subtype.

\section{Conclusions}

This study found that genetically higher serum magnesium concentrations are associated with a reduced risk of cardioembolic stroke but found no significant association of genetically higher serum calcium concentrations with any ischemic stroke subtype.

\author{
Correspondence \\ Dr. Larsson \\ susanna.larsson@ki.se
}

\section{RELATED ARTICLE}

\section{Editorial}

The yin and yang of magnesium and calcium: New genetic insights for stroke?

Page 403 


\section{Glossary}

$\mathbf{C I}=$ confidence interval; GWAS $=$ genome-wide association study; $\mathbf{M R}=$ mendelian randomization; $\mathbf{O R}=$ odds ratio; SIMEX = simulation extrapolation; SNP = single nucleotide polymorphism.

\section{Do serum calcium and magnesium levels cause ischemic stroke?}

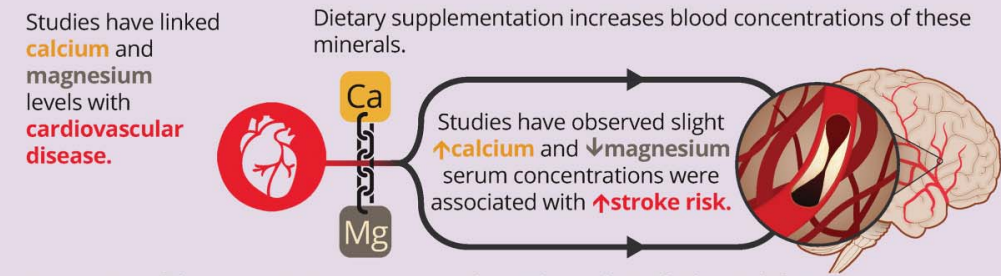

Its uncertain if these associations were casual or independent of other risk factors.

\section{Mendelian randomization (MR) approach: Infer causality of a factor by exploiting} genetic variants without bias.

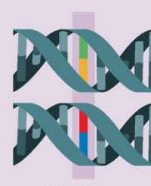

13 single nucleotide polymorphisms (SNP)

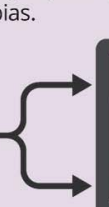

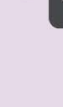

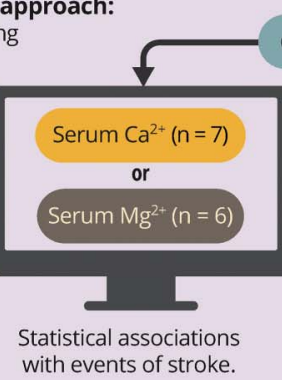

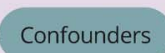

Confounders

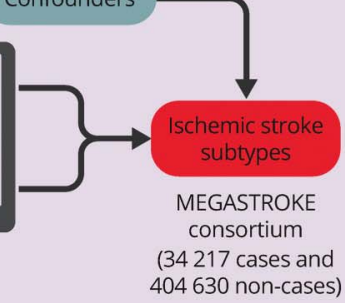

\section{Study question}

Can causal association between serum calcium and magnesium levels and ischemic stroke be determined using MR approach?

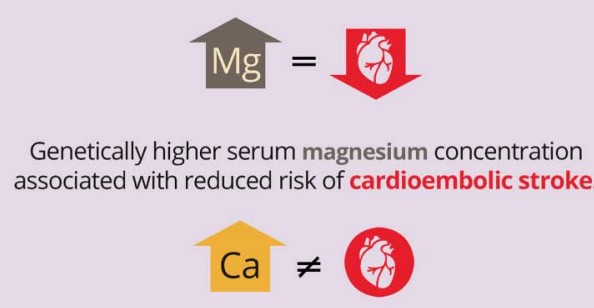

Genetically higher calcium concentration was not associated with any ischemic stroke subtype.

Genetically higher serum magnesium levels but not calcium was associated with reduced risk of stroke.

\section{Neurology}

Growing evidence indicates that the essential minerals magnesium and calcium may have a role in cardiovascular disease. Magnesium, the second most predominant intracellular cation, can influence the cardiovascular system through vascular tone, blood pressure, endothelial function, platelet aggregation and coagulation, cardiac arrhythmias, and glucose and insulin metabolism. ${ }^{1-3}$ Calcium, the most abundant mineral in the body, has an essential role in the coagulation system, intracellular signaling, and muscle contraction, but is also associated with some pathologic processes such as carotid artery plaques ${ }^{4,5}$ and calcifications. ${ }^{6}$

Magnesium and calcium supplementation leads to a rise in blood concentrations of these minerals. ${ }^{7-9}$ Therefore, any association of circulating magnesium and calcium concentrations with risk of stroke, an enormous public health problem, can have important public health and clinical implications. Findings from observational epidemiologic studies indicate that low serum magnesium concentrations ${ }^{10-12}$ and slightly elevated serum calcium concentrations ${ }^{13,14}$ are associated with increased risk of stroke. Limited data from randomized controlled trials further indicate that calcium supplementation might increase stroke risk. ${ }^{4}$ However, given the observational design of the majority of available studies on magnesium and calcium in relation to risk of stroke, it is uncertain whether the observed associations are causal and independent of other risk factors, and not biased by reverse causation.

Mendelian randomization (MR) is a genetic epidemiologic method that exploits genetic variants influencing the modifiable exposure of interest as unbiased proxies for the exposure to infer causality. ${ }^{5,15}$ This method has been utilized to demonstrate that serum magnesium ${ }^{16}$ and serum calcium ${ }^{17}$ concentrations are associated with respectively decreased and increased risk of coronary artery disease, but has not been used to determine whether circulating levels of these minerals are associated with risk of ischemic stroke. We applied a 2-sample MR approach to investigate whether serum magnesium and calcium concentrations are causally associated with ischemic stroke as a whole or any of its main subtypes.

\section{Methods}

\section{Single nucleotide polymorphism selection and data sources}

We selected all single nucleotide polymorphisms (SNPs) associated with serum magnesium or calcium concentrations at 
genome-wide significance $\left(p<5 \times 10^{-8}\right)$ in the largest published genome-wide association studies (GWAS) on these minerals. ${ }^{18,19}$ The GWAS on serum magnesium identified 6 significant and independent (i.e., not in linkage disequilibrium) SNPs, explaining $1.6 \%$ of the variance in serum magnesium concentrations, in the joint analysis of the discovery and replication cohorts including 23,829 individuals of European ancestry. ${ }^{18}$ The GWAS on serum calcium identified 7 replicated and independent SNPs, explaining 0.9\% of the variance in serum calcium concentrations, in up to 61,079 individuals of European ancestry. ${ }^{19}$

From the MEGASTROKE consortium, ${ }^{20}$ we obtained summary statistics data for stroke for the 13 SNPs. To reduce potential bias caused by population stratification, we restricted the stroke dataset to individuals of European ancestry. Thus, our analyses included data from up to 404,630 noncases and 34,217 ischemic stroke cases, subtyped into cardioembolic stroke $(\mathrm{n}=7,193)$, large artery stroke $(n=4,373)$, and small vessel stroke $(n=$ 5,386). Stroke subtypes were classified according to the Trial of Org 10172 in Acute Stroke Treatment criteria. ${ }^{21}$

\section{Standard protocol approvals, registrations, and patient consents}

Each study included in the GWAS used in the present study was approved by an institutional review board, and all participants had provided informed consent.

\section{Statistical analysis}

The primary analyses were conducted using the inversevariance weighted method (hereafter referred to as standard MR analysis), which gives accurate estimates if all SNPs satisfy the instrumental variable assumptions (data available from Open Science Framework, figure e-1, osf.io/ b57sq/). ${ }^{22}$ In sensitivity analyses, we used other MR approaches, including the following: (1) the weighted median method, which provides consistent estimates if at least $50 \%$ of the weight in the analysis comes from valid instrumental variables ${ }^{22}$; (2) the heterogeneity-penalized model averaging method, which gives consistent estimates if a plurality of the instrumental variables are valid ${ }^{23}$; and (3) the MR-Egger method, which can detect and adjust for pleiotropy. ${ }^{22,24}$ The MR-Egger analysis is disposed to regression dilution bias. The degree of dilution bias was assessed with the $I^{2}{ }_{\mathrm{GX}}$ statistic. ${ }^{25} \mathrm{I}_{\mathrm{GX}}^{2}$ values below 0.9 were considered substantial dilution, and the simulation extrapolation (SIMEX) method was used to adjust the estimates for dilution bias. ${ }^{25}$ The MR-PRESSO method was used to detect potential outliers. ${ }^{26}$ Moreover, we conducted sensitivity analyses excluding SNPs with pleiotropic associations with possible confounders or intermediates of the exposurestroke relationship.

Odds ratios (ORs) were scaled per $0.1 \mathrm{mmol} / \mathrm{L}$ (about $1 \mathrm{SD}$ ) increase in serum magnesium concentrations and $0.5 \mathrm{mg} / \mathrm{dL}$ (about $1 \mathrm{SD}$ ) increase in serum calcium concentrations. A Bonferroni-corrected level of significance of less than 0.006 (correcting for 2 exposures and 4 outcomes) was considered statistically significant. Associations of the 13 individual SNPs with the 4 outcomes were considered statistically significant at $p$ values of less than $9.6 \times 10^{-4}$. The analyses were conducted using Stata software (StataCorp, College Station, TX) and the MendelianRandomization package ${ }^{27}$ for R. Statistical power was calculated using the method proposed by Brion et al. ${ }^{28}$

\section{Data availability}

All data generated or analyzed during this study are included in the main manuscript and its supplementary information files.

\section{Results}

\section{Statistical power}

We had $100 \%$ power to detect an OR of any ischemic stroke of 0.80 for serum magnesium levels and 1.25 for serum calcium levels. The statistical power in analyses of ischemic stroke subtypes is shown in data available from Open Science Framework (table e-1, osf.io/b57sq/).

\section{Serum magnesium}

Of the 6 SNPs associated with serum magnesium concentrations, rs7965584 (near ATP2B1) was statistically significantly associated with all ischemic stroke, large artery stroke, and small vessel stroke; rs4072037 (MUC1) was associated with cardioembolic stroke; and rs448378 (MDS1) was associated with large artery stroke (data available from Open Science Framework, table 2 and figure e-1, osf.io/b57sq/). In the standard MR analysis, genetically predicted serum magnesium concentrations were associated with all ischemic stroke, cardioembolic stroke, and large artery stroke, but not with small vessel stroke (figure 1). The ORs per genetically predicted $0.1 \mathrm{mmol} / \mathrm{L}$ (about $1 \mathrm{SD}$ ) increase in serum magnesium concentrations were 0.78 (95\% confidence interval [CI] 0.69-0.89; $p=1.3 \times 10^{-4}$ ) for all ischemic stroke, 0.63 $\left(95 \%\right.$ CI $\left.0.50-0.80 ; p=1.6 \times 10^{-4}\right)$ for cardioembolic stroke, 0.60 (95\% CI 0.44-0.82; $p=0.001)$ for large artery stroke, and 0.90 (95\% CI $0.67-1.20 ; p=0.46$ ) for small vessel stroke (figure 1). Only the association with cardioembolic stroke remained in sensitivity analyses (figure 1).

The $I^{2}{ }_{\mathrm{GX}}$ value from the MR-Egger analysis was 0.87 , indicating $13 \%$ dilution of the estimates. The MR-Egger analysis, with adjustment for dilution bias using the SIMEX method, provided imprecise estimates (data available from Open Science Framework, table e-3, osf.io/b57sq/). In this analysis, genetically predicted serum magnesium concentrations were associated with cardioembolic stroke but the $\mathrm{CI}$ included the null (OR 0.66, 95\% CI 0.21-2.10); there was no evidence of directional pleiotropy (data available from Open Science Framework, table e-3). In contrast, directional pleiotropy was detected in the analysis of large artery stroke, and this was not explained by any single SNP (data available from Open Science Framework, table e-3). 
Figure 1 Association between genetically predicted serum magnesium concentrations and ischemic stroke and its subtypes

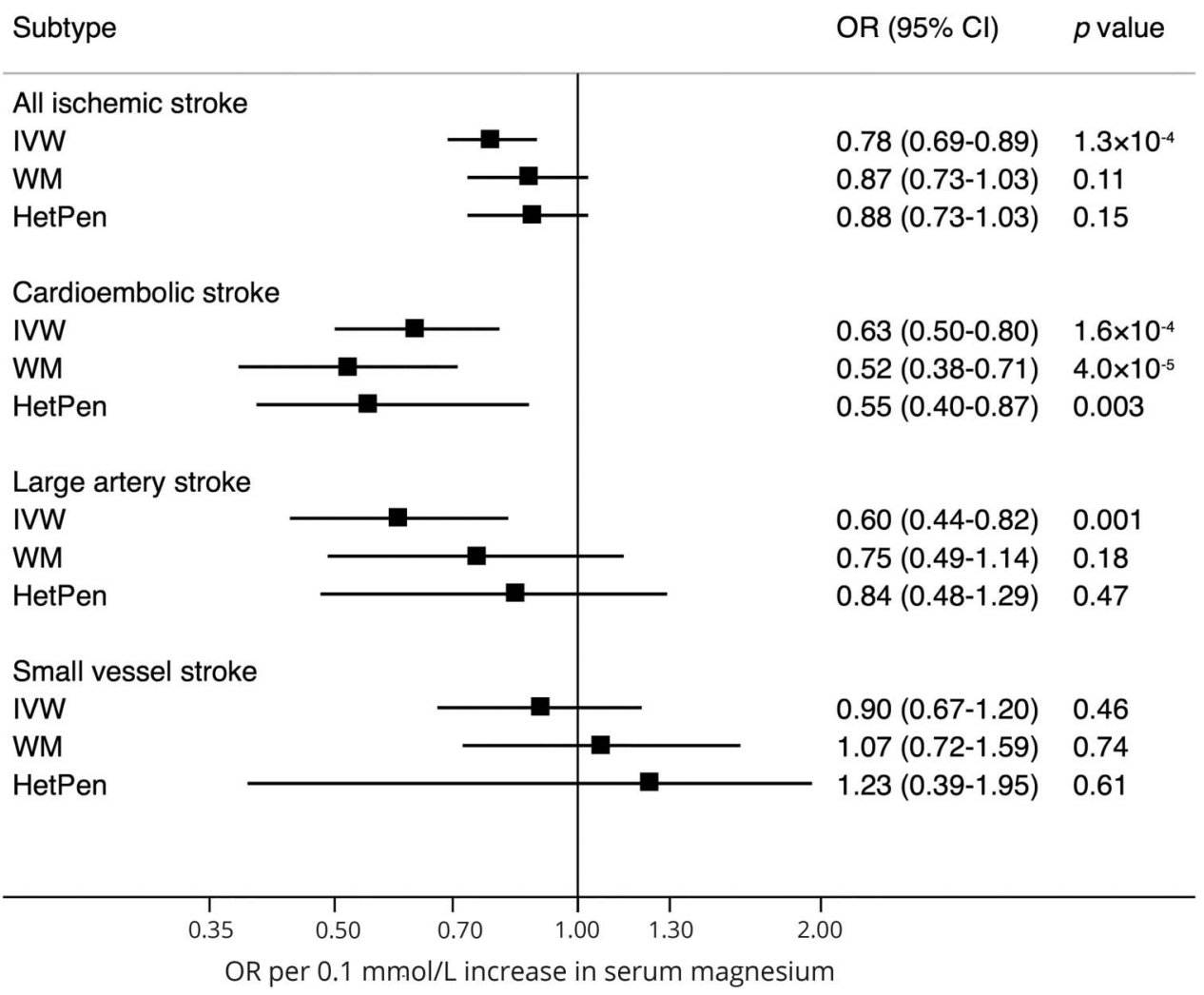

ORs are per genetically predicted 0.1 $\mathrm{mmol} / \mathrm{L}$ (about $1 \mathrm{SD}$ ) increase in serum magnesium concentrations. $\mathrm{Cl}=$ confidence interval; HetPen $=$ heterogeneity-penalized model-averaging; IVW = inverse variance weighted (standard mendelian randomization method); $\mathrm{OR}=$ odds ratio; $\mathrm{WM}=$ weighted median.
The MR-PRESSO analysis identified potential outlying SNPs (at $p<0.10$ ), which varied for different subtypes (data available from Open Science Framework, table e-4, osf.io/ b57sq/). The association of genetically predicted serum magnesium concentration with cardioembolic stroke persisted after exclusion of the outlier in TRPM6 (OR 0.56, 95\% CI 0.43-0.73). The association also remained after exclusion of 2 SNPs associated with estimated glomerular filtration rate and 1 SNP associated with blood pressure and serum urate levels, but was attenuated after omitting 2 SNPs associated with atrial fibrillation (OR 0.73, 95\% CI 0.52-1.03) (data available from Open Science Framework, table e-5).

\section{Serum calcium}

None of the calcium-associated SNPs was statistically significantly associated with ischemic stroke as a whole or any subtype (data available from Open Science Framework, table e- 6 and figure e-2, osf.io/b57sq/). There were no associations between genetically predicted serum calcium concentrations and any stroke outcome in the standard MR analysis (figure 2). The OR of all ischemic stroke per genetically predicted 0.5 $\mathrm{mg} / \mathrm{dL}$ (about $1 \mathrm{SD}$ ) increase in serum calcium concentrations was 1.03 (95\% CI $0.88-1.21 ; p=0.68$ ). The lack of association remained in sensitivity analyses (figure 2 ), and there was no evidence of directional pleiotropy in the MREgger analysis (data available from Open Science Framework, table e-7, osf.io/b57sq/). The $I^{2}{ }_{G X}$ value was 0.96 , indicating no significant dilution bias in the MR-Egger analysis. No associations of genetically predicted serum calcium concentrations with any stroke outcome were observed after exclusion of the SNP in GCKR, which has pleiotropic associations with potential confounders (e.g., blood lipids and type 2 diabetes) (data available from Open Science Framework, table e-8). ${ }^{17}$ No outliers were identified in the MRPRESSO analysis.

\section{Discussion}

Findings of this MR study showed a consistent association between genetically higher serum magnesium concentrations and reduced risk of cardioembolic stroke but not other subtypes. Genetically predicted serum calcium concentrations were not associated with any ischemic stroke subtype or with ischemic stroke overall.

Although several observational prospective studies have reported that low circulating magnesium concentrations ${ }^{10-12}$ and low magnesium intake ${ }^{29}$ are associated with increased risk of stroke, data on ischemic stroke subtypes are scarce. ${ }^{12}$ In the Nurses' Health Study, low plasma magnesium concentrations $(<0.82 \mathrm{mmol} / \mathrm{L})$ were associated with an approximately $70 \%$ 
Figure 2 Association between genetically predicted serum calcium concentrations and ischemic stroke and its subtypes

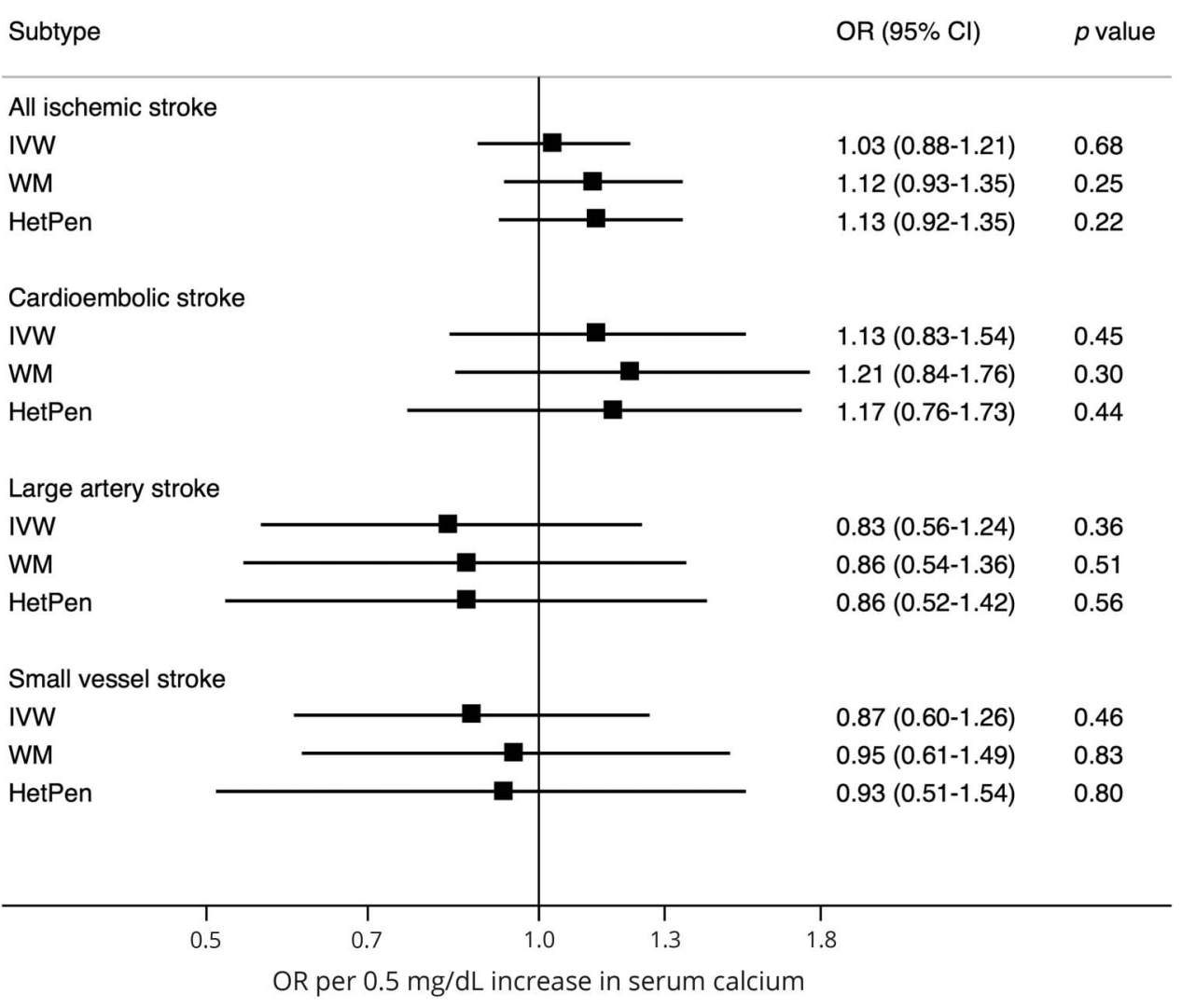

ORs are per genetically predicted 0.5 $\mathrm{mg} / \mathrm{dL}$ (about $1 \mathrm{SD}$ ) increase in serum calcium concentrations. $\mathrm{Cl}=$ confidence interval; HetPen = heterogeneity-penalized model-averaging; IVW = inverse variance weighted (standard mendelian randomization method); OR = odds ratio; $W M=$ weighted median. to $80 \%$ increased risk of embolic and thrombotic stroke, ${ }^{12}$ supporting our findings. Previous observational studies were limited by possible residual confounding because low magnesium concentrations and magnesium intake are correlated with potential risk factors for stroke. ${ }^{10-12}$

Magnesium may in part reduce the risk of cardioembolic stroke through its antiarrhythmic effects ${ }^{1,3}$ and via atrial fibrillation. Low serum magnesium concentrations are associated with increased risk of atrial fibrillation, ${ }^{30,31}$ which is a strong risk factor for cardioembolic stroke. Two of the magnesium-associated SNPs were significantly associated with atrial fibrillation, including the SNPs in the MUC1 $(p=0.02)$ and SHROOM3 ( $p=$ $2.4 \times 10^{-4}$ ) genes, with the allele associated with higher serum magnesium concentrations being associated with lower risk of atrial fibrillation. $^{32}$ The association between genetically predicted serum magnesium concentrations and cardioembolic stroke was attenuated after exclusion of those 2 SNPs, suggesting that the association may partly be mediated by atrial fibrillation.

Magnesium also has anticoagulant and antiplatelet properties. ${ }^{1,3}$ Magnesium is considered to be nature's calcium blocker as it suppresses many of the physiologic actions of calcium. ${ }^{1,3}$ For example, calcium promotes blood coagulation, whereas magnesium suppresses blood clotting and thrombus formation and reduces platelet aggregation, the synthesis of platelet agonist thromboxane A2, von Willebrand factor binding to collagen, and thrombin-stimulated calcium influx. ${ }^{1,3,33-35}$ Antithrombotic effects may lead to reduction in risk of both cardioembolic and large artery stroke. A significant association between genetically predicted serum magnesium concentrations and large artery stroke was observed in the standard MR analysis, but this association did not persist in sensitivity analyses.

Other possible mechanisms whereby high serum magnesium concentrations may reduce ischemic stroke risk include improvement of endothelial function ${ }^{36,37}$ and reduction in blood pressure, $^{36,38}$ atherosclerotic calcification, ${ }^{39}$ arterial stiffness, ${ }^{40}$ oxidative stress, ${ }^{41}$ fasting glucose concentration, ${ }^{38}$ insulin resistance, ${ }^{42}$ and risk of type 2 diabetes. ${ }^{43,44}$ Some of those beneficial effects may also lead to a reduction in small vessel stroke, which was not observed in this study.

The MR design has not been previously used to determine the association between serum calcium concentration and risk of ischemic stroke, but a few observational prospective studies have examined the association between serum calcium concentrations and risk of stroke. ${ }^{13,14}$ In a cohort of about 440,000 Swedish adults, high $(\geq 2.40 \mathrm{mmol} / \mathrm{L})$ vs low $(<2.25$ $\mathrm{mmol} / \mathrm{L})$ serum calcium concentrations were associated with a $12 \%$ increased risk of incident ischemic stroke and with 
a $40 \%$ increased risk of fatal ischemic stroke. ${ }^{14}$ Another cohort of 13,288 US adults showed a $16 \%$ increase in risk of total stroke per 1-SD increase in serum calcium concentrations. ${ }^{13}$ The association of genetically predicted serum calcium concentration with cardioembolic stroke in the present study was of similar magnitude, though nonsignificant, as the association with stroke in previous observational studies ${ }^{13,14}$ and with coronary artery disease in a previous MR study (OR 1.25, 95\% CI 1.08-1.45). ${ }^{17}$ The estimates for serum calcium and cardiometabolic stroke are also similar to those for calcium supplementation and stroke from a meta-analysis of 8 randomized controlled trials (relative risk 1.15, 95\% CI $1.00-1.32 ; p=0.06) .{ }^{4}$ It is unclear why genetically predicted serum calcium concentrations were not associated with large artery stroke, which like coronary heart disease is related to atherosclerosis. A possibility is that we may have overlooked an association because of low power (data available from Open Science Framework, table e-1, osf.io/b57sq/).

A major strength of this MR study is that biases that can be of concern in conventional observational studies were avoided. Other important strengths are the large number of cases of ischemic stroke and that associations with ischemic stroke subtypes could be investigated.

A limitation is that statistical power was low in the analyses of ischemic stroke subtypes. The power was particularly low in the analyses of calcium because the SNPs only explained a small proportion of the variance $(0.9 \%)$ in serum calcium levels. Hence, we cannot rule out that we may have overlooked weak associations between genetically predicted serum calcium concentrations and ischemic stroke subtypes. Another shortcoming is that the biological function of several of the genetic loci associated with serum magnesium and calcium levels are unknown (data available from Open Science Framework, table e-9, osf.io/b57sq/).

The reliability of $\mathrm{MR}$ results relies on 3 main assumptions (data available from Open Science Framework, figure e-1, osf. io/b57sq/), which can be violated by population stratification, canalization, and pleiotropy. Population stratification was minimized because we restricted the study populations to European-descent individuals. We could not directly test whether canalization may have influenced the results. Canalization refers to compensatory processes during development that alleviate the genetic effect. Such feedback mechanisms would bias the results toward the null and cannot explain the observed association between serum magnesium concentration and cardioembolic stroke. Pleiotropy occurs when a genetic variant is associated with more than one phenotype. We conducted several sensitivity analyses to explore and adjust for pleiotropy. The association of genetically predicted serum magnesium concentrations with cardioembolic stroke, but not the other subtypes or overall stroke, was robust in these sensitivity analyses and the MR-Egger analysis provided no evidence of directional pleiotropy.
This study found evidence that genetically higher serum magnesium concentrations may be associated with a reduced risk of cardioembolic stroke. Genetically higher serum calcium concentrations were not associated with ischemic stroke, but the existence of an effect of low magnitude cannot be ruled out.

\section{Author contributions}

Susanna C. Larsson designed the study, performed the statistical analyses, wrote the first draft of the manuscript, and drew the figures. Susanna C. Larsson is the corresponding author and takes responsibility for the accuracy of the analysis and had authority over manuscript preparation and the decision to submit the manuscript for publication. Matthew Traylor reviewed and commented on the manuscript. Stephen Burgess reviewed and commented on the manuscript. Giorgio B. Boncoraglio reviewed and commented on the manuscript. Christina Jern reviewed and commented on the manuscript. Karl Michaëlsson reviewed and commented on the manuscript. Hugh S. Markus reviewed and commented on the manuscript.

\section{Acknowledgment}

The authors thank the International Stroke Genetics Consortium for providing summary statistics data from the MEGASTROKE project. The MEGASTROKE authors are listed in the supplement. The MEGASTROKE project received funding from sources specified at megastroke.org/acknowledgments.html.

\section{Study funding}

None of the funding bodies given below had any role in the design, writing, or decision to publish this article. This work was supported by the Swedish Research Council for Health, Working Life and Welfare (Forte) and the Swedish Research Council. Hugh Markus is supported by an NIHR Senior Investigator award. His and Matthew Traylor's work is supported by infrastructural support from the Cambridge University Hospitals Trust NIHR Biomedical Research Centre.

\section{Disclosure}

The authors report no disclosures relevant to the manuscript. Go to Neurology.org/N for full disclosures.

\section{Publication history}

Received by Neurology May 9, 2018. Accepted in final form October 24, 2018.

\section{References}

1. Shechter M. Magnesium and cardiovascular system. Magnes Res 2010;23:60-72.

2. Volpe SL. Magnesium, the metabolic syndrome, insulin resistance, and type 2 diabetes mellitus. Crit Rev Food Sci Nutr 2008;48:293-300.

3. Kolte D, Vijayaraghavan K, Khera S, Sica DA, Frishman WH. Role of magnesium in cardiovascular diseases. Cardiol Rev 2014;22:182-192.

4. Bolland MJ, Grey A, Avenell A, Gamble GD, Reid IR. Calcium supplements with or without vitamin D and risk of cardiovascular events: reanalysis of the Women's Health Initiative limited access dataset and meta-analysis. BMJ 2011;342:d2040.

5. Burgess S, Thompson SG. Mendelian Randomization: Methods for Using Genetic Variants in Causal Estimation. Boca Raton: Chapman and Hall/CRC Press; 2015.

6. Reid IR, Gamble GD, Bolland MJ. Circulating calcium concentrations, vascular disease and mortality: a systematic review. J Intern Med 2016;279:524-540.

7. Bristow SM, Gamble GD, Stewart A, et al. Acute and 3-month effects of microcrystalline hydroxyapatite, calcium citrate and calcium carbonate on serum calcium and 
markers of bone turnover: a randomised controlled trial in postmenopausal women. Br J Nutr 2014;112:1611-1620.

8. Bristow SM, Gamble GD, Stewart A, Kalluru R, Horne AM, Reid IR. Acute effects of calcium citrate with or without a meal, calcium-fortified juice and a dairy product meal on serum calcium and phosphate: a randomised cross-over trial. Br J Nutr 2015;113: 1585-1594.

9. Zhang X, Del Gobbo LC, Hruby A, et al. The circulating concentration and 24-h urine excretion of magnesium dose- and time-dependently respond to oral magnesium supplementation in a meta-analysis of randomized controlled trials. J Nutr 2016;146: 595-602.

10. Zhang X, Xia J, Del Gobbo LC, Hruby A, Dai Q, Song Y. Serum magnesium concentrations and all-cause, cardiovascular, and cancer mortality among U.S. adults: results from the NHANES I Epidemiologic Follow-up Study. Clin Nutr 2018;37:1541-1549.

11. Ohira T, Peacock JM, Iso H, Chambless LE, Rosamond WD, Folsom AR. Serum and dietary magnesium and risk of ischemic stroke: the Atherosclerosis Risk in Communities Study. Am J Epidemiol 2009;169:1437-1444.

12. Adebamowo SN, Jimenez MC, Chiuve SE, Spiegelman D, Willett WC, Rexrode KM. Plasma magnesium and risk of ischemic stroke among women. Stroke 2014;45: 2881-2886.

13. Foley RN, Collins AJ, Ishani A, Kalra PA. Calcium-phosphate levels and cardiovascular disease in community-dwelling adults: the Atherosclerosis Risk in Communities (ARIC) Study. Am Heart J 2008;156:556-563.

14. Rohrmann S, Garmo H, Malmstrom H, et al. Association between serum calcium concentration and risk of incident and fatal cardiovascular disease in the prospective AMORIS study. Atherosclerosis 2016;251:85-93.

15. Smith GD, Ebrahim S. 'Mendelian randomization': can genetic epidemiology contribute to understanding environmental determinants of disease? Int J Epidemiol 2003;32:1-22.

16. Larsson SC, Burgess S, Michaëlsson K. Serum magnesium levels and risk of coronary artery disease: mendelian randomisation study. BMC Med 2018;16:68.

17. Larsson SC, Burgess S, Michaelsson K. Association of genetic variants related to serum calcium levels with coronary artery disease and myocardial infarction. JAMA 2017;318:371-380.

18. Meyer TE, Verwoert GC, Hwang SJ, et al. Genome-wide association studies of serum magnesium, potassium, and sodium concentrations identify six loci influencing serum magnesium levels. PLoS Genet 2010;6:e1001045.

19. O'Seaghdha CM, Wu H, Yang Q, et al. Meta-analysis of genome-wide association studies identifies six new loci for serum calcium concentrations. PLoS Genet 2013;9: e1003796.

20. Malik R, Chauhan G, Traylor M, et al. Multiancestry genome-wide association study of 520,000 subjects identifies 32 loci associated with stroke and stroke subtypes. Nat Genet 2018;50:524-537.

21. Adams HP Jr, Bendixen BH, Kappelle LJ, et al. Classification of subtype of acute ischemic stroke. Definitions for use in a multicenter clinical trial. TOAST. Trial of Org 10172 in Acute Stroke Treatment. Stroke 1993;24:35-41.

22. Burgess S, Bowden J, Fall T, Ingelsson E, Thompson SG. Sensitivity analyses for robust causal inference from mendelian randomization analyses with multiple genetic variants. Epidemiology 2017;28:30-42.

23. Burgess S, Zuber V, Gkatzionis A, Foley CN. Modal-based estimation via heterogeneity-penalized weighting: model averaging for consistent and efficient estimation in mendelian randomization when a plurality of candidate instruments are valid. Int J Epidemiol 2018;47:1242-1254.

24. Burgess S, Thompson SG. Interpreting findings from mendelian randomization using the MR-Egger method. Eur J Epidemiol 2017;32:377-389.

25. Bowden J, Del Greco MF, Minelli C, Davey Smith G, Sheehan NA, Thompson JR. Assessing the suitability of summary data for two-sample mendelian randomization analyses using MR-Egger regression: the role of the $\mathrm{I}^{2}$ statistic. Int J Epidemiol 2016; 45:1961-1974.

26. Verbanck M, Chen CY, Neale B, Do R. Detection of widespread horizontal pleiotropy in causal relationships inferred from mendelian randomization between complex traits and diseases. Nat Genet 2018;50:693-698.

27. MendelianRandomization: Mendelian Randomization Package [online]. Available at: CRAN.R-project.org/package $=$ MendelianRandomization. Accessed September 11, 2018.

28. Brion MJ, Shakhbazov K, Visscher PM. Calculating statistical power in mendelian randomization studies. Int J Epidemiol 2013;42:1497-1501.

29. Larsson SC, Orsini N, Wolk A. Dietary magnesium intake and risk of stroke: a metaanalysis of prospective studies. Am J Clin Nutr 2012;95:362-366.

30. Khan AM, Lubitz SA, Sullivan LM, et al. Low serum magnesium and the development of atrial fibrillation in the community: the Framingham Heart Study. Circulation 2013;127:33-38.

31. Misialek JR, Lopez FL, Lutsey PL, et al. Serum and dietary magnesium and incidence of atrial fibrillation in whites and in African Americans: Atherosclerosis Risk in Communities (ARIC) study. Circ J 2013;77:323-329.

32. Roselli C, Chaffin MD, Weng LC, et al. Multi-ethnic genome-wide association study for atrial fibrillation. Nat Genet 2018;50:1225-1233.

33. Kh R, Khullar M, Kashyap M, Pandhi P, Uppal R. Effect of oral magnesium supplementation on blood pressure, platelet aggregation and calcium handling in deoxycorticosterone acetate induced hypertension in rats. J Hypertens 2000;18:919-926.

34. Shechter M, Merz CN, Paul-Labrador M, et al. Oral magnesium supplementation inhibits platelet-dependent thrombosis in patients with coronary artery disease. Am J Cardiol 1999;84:152-156.

35. Dong JF, Cruz MA, Aboulfatova K, et al. Magnesium maintains endothelial integrity, up-regulates proteolysis of ultra-large von Willebrand factor, and reduces platelet aggregation under flow conditions. Thromb Haemost 2008;99:586-593.

36. Cunha AR, D'El-Rei J, Medeiros F, et al. Oral magnesium supplementation improves endothelial function and attenuates subclinical atherosclerosis in thiazide-treated hypertensive women. J Hypertens 2017;35:89-97.

37. Shechter M, Sharir M, Labrador MJ, Forrester J, Silver B, Bairey Merz CN. Oral magnesium therapy improves endothelial function in patients with coronary artery disease. Circulation 2000;102:2353-2358.

38. Verma H, Garg R. Effect of magnesium supplementation on type 2 diabetes associated cardiovascular risk factors: a systematic review and meta-analysis. J Hum Nutr Diet 2017;30:621-633.

39. Hruby A, O’Donnell CJ, Jacques PF, Meigs JB, Hoffmann U, McKeown NM. Magnesium intake is inversely associated with coronary artery calcification: the Framingham Heart Study. JACC Cardiovasc Imaging 2014;7:59-69.

40. Joris PJ, Plat J, Bakker SJ, Mensink RP. Long-term magnesium supplementation improves arterial stiffness in overweight and obese adults: results of a randomized, double-blind, placebo-controlled intervention trial. Am J Clin Nutr 2016;103: $1260-1266$.

41. Morais JB, Severo JS, Santos LR, et al. Role of magnesium in oxidative stress in individuals with obesity. Biol Trace Elem Res 2017;176:20-26.

42. Simental-Mendia LE, Sahebkar A, Rodriguez-Moran M, Guerrero-Romero F. A systematic review and meta-analysis of randomized controlled trials on the effects of magnesium supplementation on insulin sensitivity and glucose control. Pharmacol Res 2016;111:272-282

43. Larsson SC, Wolk A. Magnesium intake and risk of type 2 diabetes: a meta-analysis. J Intern Med 2007;262:208-214.

44. Wu J, Xun P, Tang Q, Cai W, He K. Circulating magnesium levels and incidence of coronary heart diseases, hypertension, and type 2 diabetes mellitus: a meta-analysis of prospective cohort studies. Nutr J 2017;16:60. 


\section{Neurology}

\section{Serum magnesium and calcium levels in relation to ischemic stroke: Mendelian randomization study \\ Susanna C. Larsson, Matthew Traylor, Stephen Burgess, et al.}

Neurology 2019;92;e944-e950 Published Online before print January 25, 2019

DOI 10.1212/WNL.0000000000007001

This information is current as of January 25, 2019

Updated Information \& Services

References

Citations

Subspecialty Collections

Permissions \& Licensing

Reprints including high resolution figures, can be found at: http://n.neurology.org/content/92/9/e944.full

This article cites 42 articles, 9 of which you can access for free at: http://n.neurology.org/content/92/9/e944.full\#ref-list-1

This article has been cited by 2 HighWire-hosted articles: http://n.neurology.org/content/92/9/e944.full\#\#otherarticles

This article, along with others on similar topics, appears in the following collection(s):

All Cerebrovascular disease/Stroke

http://n.neurology.org/cgi/collection/all_cerebrovascular_disease_strok e

Association studies in genetics

http://n.neurology.org/cgi/collection/association_studies_in_genetics

Risk factors in epidemiology

http://n.neurology.org/cgi/collection/risk_factors_in_epidemiology

Stroke prevention

http://n.neurology.org/cgi/collection/stroke_prevention

Information about reproducing this article in parts (figures,tables) or in its entirety can be found online at:

http://www.neurology.org/about/about_the_journal\#permissions

Information about ordering reprints can be found online:

http://n.neurology.org/subscribers/advertise

Neurology ${ }^{\circledR}$ is the official journal of the American Academy of Neurology. Published continuously since 1951, it is now a weekly with 48 issues per year. Copyright Copyright ( 2019 The Author(s). Published by Wolters Kluwer Health, Inc. on behalf of the American Academy of Neurology.. All rights reserved. Print ISSN: 0028-3878. Online ISSN: 1526-632X.

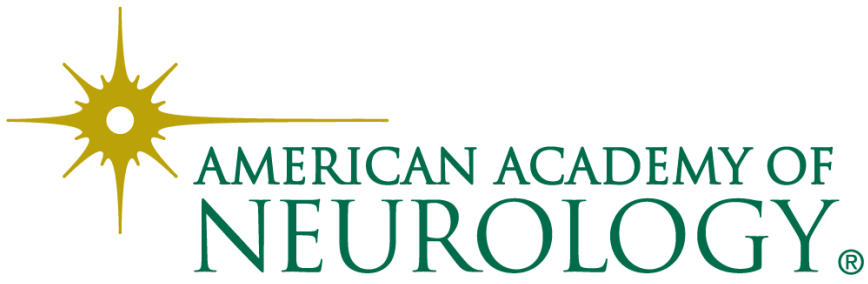

